\title{
Microbes, Immunity, and Behavior: Psychoneuroimmunology Meets the Microbiome
}

\author{
Timothy G Dinan ${ }^{\star, 1,2}$ and John F Cryan ${ }^{1,3}$ \\ ${ }^{1}$ APC Microbiome Institute, University College Cork, Cork, Ireland; ${ }^{2}$ Department of Psychiatry \& Neurobehavioural Sciences, \\ University College Cork, Cork, Ireland; ${ }^{3}$ Department of Anatomy and Neuroscience, University College Cork, Cork, Ireland
}

There is now a large volume of evidence to support the view that the immune system is a key communication pathway between the gut and brain, which plays an important role in stress-related psychopathologies and thus provides a potentially fruitful target for psychotropic intervention. The gut microbiota is a complex ecosystem with a diverse range of organisms and a sophisticated genomic structure. Bacteria within the gut are estimated to weigh in excess of $1 \mathrm{~kg}$ in the adult human and the microbes within not only produce antimicrobial peptides, short chain fatty acids, and vitamins, but also most of the common neurotransmitters found in the human brain. That the microbial content of the gut plays a key role in immune development is now beyond doubt. Early disruption of the host-microbe interplay can have lifelong consequences, not just in terms of intestinal function but in distal organs including the brain. It is clear that the immune system and nervous system are in continuous communication in order to maintain a state of homeostasis. Significant gaps in knowledge remain about the effect of the gut microbiota in coordinating the immune-nervous systems dialogue. However, studies using germ-free animals, infective models, prebiotics, probiotics, and antibiotics have increased our understanding of the interplay. Early life stress can have a lifelong impact on the microbial content of the intestine and permanently alter immune functioning. That early life stress can also impact adult psychopathology has long been appreciated in psychiatry. The challenge now is to fully decipher the molecular mechanisms that link the gut microbiota, immune, and central nervous systems in a network of communication that impacts behavior patterns and psychopathology, to eventually translate these findings to the human situation both in health and disease. Even at this juncture, there is evidence to pinpoint key sites of communication where gut microbial interventions either with drugs or diet or perhaps fecal microbiota transplantation may positively impact mental health.

Neuropsychopharmacology Reviews (2017) 42, 178-192; doi:I0.1038/npp.2016.103; published online 13 July 2016

\section{INTRODUCTION}

Although the field of psychoneuroimmunology emerged in the 1970s, it took a number of decades for the concept of the bidirectional communication between the immune system and central nervous system to gain mainstream attention in medicine (Ader et al, 1995; Glaser and Kiecolt-Glaser, 2005) There is now an overwhelming body of evidence to support the view that immune alterations occur in response to both psychological and physical stress and dysregulation of the immune system is viewed by many as a key component of psychiatric disorders such as major depression (Dinan, 2009). Over the past decade, the brain-gut axis has become an increasing focus of neuroscience research, and there is a large volume of data to indicate that the immune system is a major communication pathway between gut microbes and brain, which may play an important role in stress-related

${ }^{*}$ Correspondence: Professor TG Dinan, Department of Psychiatry, Biosciences Institute, University College Cork, Cork IE0000, Ireland, Tel: +353214901759, Fax: +3534922584; E-mail: t.dinan@ucc.ie

Received 7 April 2016; revised 26 May 2016; accepted 13 June 2016; accepted article preview online 20 June 2016 psychopathologies and thus provides a potentially fruitful target for novel psychotropic development (El Aidy et al, 2015) The focus of this review is to explore the mechanisms through which the brain-gut-microbiota axis regulates immune responses and in so doing impacts behavior, both normal and pathological. We will describe the microbiota changes from infancy to old age and examine ways in which gut microbes may be manipulated to improve mental health.

\section{GUT MICROBIOTA ESTABLISHMENT}

The gut microbiota is a complex ecosystem with a diverse range of organisms and a sophisticated genomic structure. Bacteria within the gut are estimated to weigh in excess of $1 \mathrm{~kg}$ in the adult human and the microbes within, produce not just antimicrobial peptides but short chain fatty acids (SCFAs), vitamins and intriguingly most of the common neurotransmitters found in the brain. That the microbial content of the gut plays a key role in immune development is generally acknowledged. 
The composition and function of the intestinal microbiota has been the subject of intense scrutiny and debate, initially using culture-dependent microbiological techniques that have significant limitations (Vaughan et al, 2000) and more recently, using culture-independent 16S rRNA gene sequence-based techniques, which allow greater insight into the microbial composition and diversity of this complex ecosystem and as a result has greatly expanded knowledge in the field (Qin et al, 2010). Such advances in metagenomic technologies have revealed the composition of the human gut microbiota from early infancy (Palmer et al, 2007) through to old age (Claesson et al, 2011), but far less is known about the physiological impact this microbiota has on host health. Advances in our knowledge of microbial structure have far outpaced our understanding in relation to function. Indeed, understanding the influence of the gut microbiota on host health is viewed as one of the most important fields across all aspects of biomedicine (Shanahan, 2012). For example, a perturbed microbiota has been implicated in an everincreasing list of disorders in humans, from necrotizing enterocolitis (NEC) in infants to obesity, autism spectrum disorder, diabetes, metabolic syndrome, irritable bowel syndrome (IBS), and inflammatory bowel disease (Kosloske, 1984; Ley et al, 2006; Kassinen et al, 2007; Peterson et al, 2008; Flint et al, 2010). As a result, the gut microbiota is increasingly becoming a target for drug and dietary therapy to treat such disorders, as well as a source of novel drugs and bioactive compounds (Shanahan, 2012).

While the GI tract of the fetus was thought to be sterile, recent evidence suggests that bacteria are present in the amniotic fluid (Jimenez et al, 2008) and also the placenta (Wassenaar and Panigrahi, 2014). During the delivery process microbes are acquired from the mother's fecal and vaginal flora and subsequently from the environment, in most developed countries the hospital environment. These begin to colonize the infant gut with a dense and intricate microbiota which subsequently develops in the full-term infant (Adlerberth and Wold, 2009). This early colonization is critical for the development of the immune system. This rapid colonization process and the microbial composition of the neonatal gut are influenced by a number of factors including antibiotic use, diet, mode of delivery, environmental factors, and the maternal microbiota (Adlerberth and Wold, 2009; Marques et al, 2010). The microbiota of formula-fed infants has been reported to be more diverse than breast-fed infants, containing higher proportions of Bacteroides, Clostridium, and Enterobacteriaceae. While vaginally delivered infants are colonized by the fecal and vaginal bacteria of the mother, infants delivered by caesarean section are colonized by other bacteria from environmental sources including health-care workers, air, equipment, and other newborns (Penders et al, 2006; Adlerberth and Wold, 2009). Efforts to replicate the intestinal microbiota of breastfed infants via formula-feeding has been a major challenge for the food industry and has led to the incorporation of prebiotics in infant formula; nondigestible food ingredients that selectively stimulate the growth and/or activity of one or more bacterial species in the colon beneficially affecting the host (Gibson and Roberfroid, 1995). It has been reported that a combination of galacto-oligosaccharides (GOS) and fructooligosaccharides (FOS), at ratios similar to the oligosaccharide composition of human breast milk, can stimulate the growth of bifidobacteria and influence species distribution in the gut microbiota, as well as altering fecal $\mathrm{pH}$ and SCFA production levels to mimic those of breast-fed infants (Fanaro et al, 2005; Haarman and Knol, 2005). Prebiotics are also known to play a role in the neonatal immune system and protect against pathogens (Boehm and Moro, 2008; Saulnier et al, 2009). Preclinical data from our laboratory indicate that such prebiotics can dramatically impact stress responses both endocrine and behavioral (Burokas et al, in press).

The intestinal microbiota of newborn infants is characterized by low diversity and a relative dominance of the phyla Proteobacteria and Actinobacteria in the early postnatal period. With the passage of time, the microbiota becomes more diverse with the emergence and dominance of Firmicutes and Bacteroidetes (Eckburg et al, 2005; Qin et al, 2010; Backhed, 2011). Full-term, vaginally delivered babies born to healthy mothers who are breast fed and nonantibiotic treated have an optimal development of the neonatal microbiota (Penders et al, 2006). In these infants, facultative anaerobes such as enterobacteria, staphylococci, and streptococci are the earliest to colonize, taking advantage of the redox potential and available oxygen of the newborn GI tract (Stark and Lee, 1982; Mackie et al, 1999). Earliest colonizers consume the oxygen in the GI tract and generate an anaerobic environment allowing the proliferation of strict anaerobes, Clostridium, Bacteroides, and Bifidobacteria, with the latter becoming dominant and outnumbering all other bacterial groups in the first weeks of life (Harmsen et al, 2000; Penders et al, 2006). The neonatal microbiota is highly dynamic and is characterized by rapid change and low diversity (Penders et al, 2006; Adlerberth and Wold, 2009). By the end of the first year of life, infants possess a microbial profile distinct for each infant, converging towards the characteristic microbiota of an adult and within 3 years of age the microbiota fully resembles that of an adult in terms of composition (Palmer et al, 2007; Koenig et al, 2011; Barrett et al, 2015).

The characteristic intestinal microbiota observed in healthy full-term infants is disturbed in preterm infants (Dennison, 1976), who are frequently delivered by C. section, receive antibiotics, and may have problems feeding (Hoy et al, 2000). Furthermore, preterm infants possess a functionally immature gut with low levels of acidity in the stomach, due to insufficient gastric acid secretion and their requirement for more frequent feeding (Sondheimer and Clark, 1985; Sondheimer et al, 1985; Hoy et al, 2000). These events lead to an increase in the prevalence of potentially pathogenic bacteria in the GI tract and less microbial diversity than full-term infants (Chang et al, 2011; Jacquot et al, 2011; Arboleya et al, 2012). It has be opined that the dysregulated intestinal microbiota of preterm infants is a risk factor for the increased susceptibility to systemic infection and the development of NEC, which remains a common 
cause of morbidity and mortality in preterm infants (Claud and Walker, 2001; Westerbeek et al, 2006; Deshpande et al, 2007; Neu and Walker, 2011). NEC is a life-threatening GI tract illness, causing necrosis of the intestine and can affect other organs of the body, including the brain with subsequent consequences which are far worse than the damage to the GI tract. NEC affects $5-10 \%$ of infants born with a birth-weight of less than $1500 \mathrm{~g}$ and despite advances in neonatal care is fatal in up to $30 \%$ of cases (Fitzgibbons et al, 2009) and associated with long-term intellectual disability. Recently, the use of probiotics in the treatment of NEC has been advocated (Embleton and Yates, 2008; Mshvildadze and Neu, 2009; Gareau et al, 2010).

\section{ADULT MICROBIOTA}

The adult microbiota, while more complex than that of the neonate, is relatively stable over time (Vaughan et al, 2000). There are large interpersonal differences in the microbiota of healthy adults, even between monozygotic twins, but nonetheless a shared core gut microbiome exists, exerting a common functionality within the host (Turnbaugh et al, 2010; Burke et al, 2011). The adult microbiota is dominated by members of the Bacteroidetes and Firmicutes phyla (Turnbaugh et al, 2006) and recently three different 'enterotypes' have been described (Arumugam et al, 2011). The three distinct 'enterotypes' are dominated by Prevotella, Ruminococcus, and Bacteroides, and are described as independent of sex, age, nationality, and body mass index. Although there are those who advocate this enterotype classification, it can be criticized on the grounds of oversimplification. What seems clear is that the composition of the human microbiota is determined by an interaction of host genetics and diet with the environment, which includes chemicals such as antibiotics (Rawls et al, 2006; Benson et al, 2010). It has been suggested that diet may be the easiest way to alter the host microbiota and that such changes may come about rapidly (Wu et al, 2011). However, a recent study in rodents suggests this may not be as easy as it seems (Sonnenburg et al, 2016). They raised mice in a germ-free (GF) environment and then transplanted a human microbiota. When fed a low-fiber diet, the animals showed a substantial drop in gut microbial diversity. Furthermore, mice kept on a low-fiber food and allowed to breed produced offspring with an even lower diversity and subsequent generations of low-fiber-fed mice continued to lose whole groups of microbes. By the fourth generation, the mouse microbiota seemed to have reached a stable low-diversity, with only a quarter of the diversity of the first generation. Perhaps the most important finding in the study is that none of the low-fiber generations could be 'rescued' by reintroducing high-fiber food. If these findings are replicated in humans it raises major questions regarding poor diet, especially in families of low socio-economic status and the potential for trans-generational negative health consequences.
TABLE 1 Gut Microbiota Composition Throughout the Life Span

\begin{tabular}{lll}
\hline & Composition & References \\
\hline Neonatal & $\begin{array}{l}\text { Low diversity and a relative dominance of } \\
\text { the phyla Proteobacteria and Actinobacteria }\end{array}$ & $\begin{array}{l}\text { Eckburg et al (2005), } \\
\text { Qin et al (20l0) }\end{array}$ \\
Adult & $\begin{array}{l}\text { Dominated by members of the Bacteroidetes } \\
\text { and Firmicutes phyla }\end{array}$ & $\begin{array}{l}\text { Turnbaugh et al (2006) } \\
\text { Old age }\end{array}$ \\
$\begin{array}{l}\text { Bacteroides and Firmicutes are the dominant } \\
\text { phyla } \\
\text { Significant loss of diversity especially in frail } \\
\text { elderly }\end{array}$ & Claesson et al (201 I) \\
\hline
\end{tabular}

\section{ELDERLY MICROBIOTA}

Given the fact that the ageing population is increasing rapidly as people live longer in most developed countries, the state of the gut microbiota and the relationship with common medical conditions seen in the elderly is of major importance (Mariat et al, 2009). In reality our knowledge of the mutating microbiota from adulthood into old age is poorly understood. It seems clear that the adult microbiota remains stable into old age except when confronted with antibiotics or other insults which include disease pathology, dramatic changes in diet or medications used to treat a variety of illnesses (Mariat et al, 2009; O'Toole and Claesson, 2010; Clemente et al, 2012). Differences in the microbiota of elderly subjects across Europe have been reported upon (Mueller et al, 2006). In Ireland the Eldermet consortium at University College Cork was established to characterizing the gut microbiota of elderly Irish subjects and to develop functional foods for this population. The consortium used pyrosequencing to examine over 40000 reads per sample from 161 subjects. Bacteroides and Firmicutes were identified as the dominant phyla in the distal gut of the elderly population, accounting for $97 \%$ of the assigned sequences. However, there were major variations at phylum level from one subject to the next: Firmicutes varied from 8 to $80 \%$ and Bacteroidetes varied from 14 to $92 \%$ (Claesson et al, 2011). When subjects in nursing homes were compared with those in the community, large-scale differences were detected. Those in nursing homes have a far less diverse microbiota and this was attributed to a less varied diet. However, it is possible that pathological factors that lead to admission into nursing homes such as deteriorating cognitive function might have played an important role in the decreased microbial diversity and not the less diverse diet Table 1 .

\section{MICROBES AND IMMUNITY}

Until the late nineteenth century microbes were viewed as harmful pathogens that cause infections and the host immune system was seen as developed to recognize and eradicate these invaders (Surana and Kasper, 2014). We now know that the development of the immune system is pivotally dependent on colonization with commensal microbes (Kostic et al, 2013). While multiple pathways exist for bacteria to communicate with their host, pattern 
recognition receptors (ie Toll-like receptors, TLRs) on host cells play a pivotal role. At least 10 TLRs are present on cells of the innate immune system in man and recognize characteristic molecular patterns (Frieri and Stampfl, 2016). These receptors are the gateway to the innate immune system and are a first step in the cascade leading to cytokine production. They are also universally distributed on neurons, thus allowing them to respond to bacterial and viral components (Reis et al, 2015). While the intestinal epithelium and the mucus layer acts largely as a barrier to translocation of microorganisms into the internal milieu, the nervous system is prepared and capable of responding to such interactions (Johansson et al, 2013).

The initial microbial colonization results in significant changes in mucosal and systemic immunity. The maturation of the immune system, initiated within the fetus, is highly dynamic in character and mutates over time through the first neonatal months and into childhood (Newburg and Walker, 2007). Neonates have low expression of co-stimulatory molecules, diminished dendritic cell (DC) differentiation, impaired phagocytosis as well as defective interaction between DCs, $\mathrm{T}$ lymphocytes and regulatory $\mathrm{T}$ cells and impaired cytotoxic activity of $\mathrm{T}$ cells (Kotiranta-Ainamo et al, 2004; Velilla et al, 2006). Furthermore, the activity of the transplacentally derived maternal immunoglobulin G antibodies results in a deficiency of specific humoral responses, which include minimal levels of IgA in neonates (Keles et al, 2010). Similar findings have been reported in animal studies. For example, in GF mice and those in the first days of colonization smaller Peyer's patches and low level cellularity of the lamina propria and low $\mathrm{Cd} 4^{+}$and $\mathrm{Cd} 8^{+}$ $\mathrm{T}$ cells are reported (Wei et al, 2010; El Aidy et al, 2012). Furthermore, intraepithelial lymphocytes and plasma cells are rare in the small intestinal mucosa while secretory immunoglobulin A (sIgA) levels are significantly lower with suppressed expression of genes and markers of activation for intestinal macrophages (Mikkelsen et al, 2004; El Aidy et al, 2012). Interestingly, recent evidence using GF animals also points to a role for the maternal microbiota in influencing early postnatal innate immune development in the infant. In this study monocolonization of GF animals with Escherichia coli HA107 during pregnancy altered the numbers of early postnatal intestinal innate leukocytes and increased small intestinal innate lymphoid cell (ILC) proportions and total numbers compared with GF controls, particularly the NKp46 ${ }^{+}$ROR $y t^{+}$ILC3 subset (Gomez de Aguero et al, 2016).

Secretory immunoglobulin A provides a good example of how the microbiota mediates host physiology through immune modulation. Secretory immunoglobulin A binds to luminal bacteria and prevents microbial translocation across the epithelial barrier (Macpherson et al, 2005). It also plays a role in influencing the balance of immune and metabolic pathways in the intestinal epithelium through a microbiotadependent mechanism (Shulzhenko et al, 2011). In the absence of IgA, a shift towards the expression of genes involved in host defense emerges, with excessive production of antimicrobial proteins and pro-inflammatory responses to compensate for the deficiency in microbial compartmentalization via the sIgA. In marked contrast, when IgA is present, the intestinal microbiota alters the expression of genes involved in lipid metabolism and storage; as a result there is a shift towards a microbiota-immune-metabolic response which is fundamental for homeostasis (Shulzhenko et al, 2011; El Aidy et al, 2013).

Maturation of the host immune system is dependent upon interaction with the microbiota and requires specific strains of the microbes that flourish in an environment enriched by the inflammatory processes (Chung et al, 2012; El Aidy et al, 2014). While many questions remain, it seems that these specific bacteria activate mucosal immune priming for the bacterial sampling process in order to minimize their exposure to the systemic immune system by transient breaching of the epithelial barrier, thus stimulating the production of antimicrobial molecules and significant immune pro-inflammatory and regulatory immune proteins (Mazmanian et al, 2005; Galindo-Villegas et al, 2012; El Aidy et al, 2014). The initial close highly regulated contact benefits the host by augmenting gut barrier function and enhancing protection against subsequent invading pathogens. Segmented filamentous bacteria (SFB) are a well-studied intriguing example of initial microbial-host interaction. In mice, it has been shown that after weaning SFB adhere transiently to the surface epithelium of the ileum and Peyer's patches (Gaboriau-Routhiau et al, 2009) inducing Th17 cells in the intestinal lamina propria by a mechanism that involving serum amyloid A (Gaboriau-Routhiau et al, 2011). Segmented filamentous bacteria not only induce Th17 in the GI tract, but also the effect seems to expand to the CNS (Lee et al, 2011), Understanding this complex process has implications not just for understanding gut pathology but brain immune disorders also. Studies in GF and ex-GF mice have helped increase understanding of how the gut microbiota programs the intestinal mucosa to maintain a balanced immune response within a few days of colonization (El Aidy et al, 2012; El Aidy and Kleerebezem, 2013). There is now no doubt that early life results in the most extensive alterations in host biology in response to the colonization of the microbiota. As we have previously pointed out the host encounters challenges, which elicit responses that involve activation of gene networks associated with several illnesses (El Aidy et al, 2016). Abnormal shifts during the infant's developmental path through this early rapidly mutating phase may thus have long-term health consequences (Costello et al, 2012). We have suggested that there is a critical window of development during the early life that allows for a full-scale establishment of an adequate hostmicrobial homeostasis; aberrant responses during this window can result in significant pathology later in life (Borre et al, 2014).

After initial priming by the gut microbiota, the immune system is continuously stimulated by several structural components of the microbial cells via TLRs and responds by creating a diverse range of lymphocytes and cytokines. In the absence of stressors, the gut microbiota produces a 
chronic state of ultra-low-level activation of the immune system, where bacterial components stimulate macrophages and $\mathrm{T}$ cells to create pro-inflammatory cytokines such as IL-1 $\beta$, tumor necrosis factor alpha (TNF- $\alpha$ ), and IL-18 (Heumann et al, 1994; Ulevitch and Tobias, 1995). These cytokines generate a basal state of immune activation commencing at the intestinal mucosal surface but eventually affects the entire body. It is estimated that the adult human contain $1 \mathrm{~g}$ of lipopolysaccharides and the exposure of immune cells to these cell wall molecules is essential for the maintenance of mucosal homeostasis (Bested et al, 2013). The precise molecular mechanisms that underlie aspects of host immune-microbe interaction lack clarity. However, one important factor is the regulation of the chemokine CXCL16, which is important for natural killer (iNK) T-cell migration and homeostasis. This chemokine regulation has been shown to occur through epigenetic changes involving the reduction of methylation pattern of the CXCl16 gene and in so doing reducing the number of invariant NK T cells in the colonic lamina propria (Olszak et al, 2012). Bacteroides fragilis (B. fragilis) provides another example of a factor critical for the normal function of the immune system by producing glycosphingolipid which in turn inhibits natural killer T cells proliferation in the colonic lamina propria (Wieland Brown et al, 2013). B. fragilis polysaccharide A (PSA) is recognized by TLR2 on DCs and this interaction induces colonic regulatory T cells (Tregs) (Round and Mazmanian, 2009). Such Tregs are also induced by Clostridium species, possibly by production of SCFAs (Atarashi et al, 2011). There is a marked difference between Tregs induced by B. fragilis and Clostridium species in that the latter stimulate Tregs in both normal and inflamed tissue while $B$. fragilis induces Tregs only in the presence of inflammation (Surana and Kasper, 2014). These findings indicate that when commensals leave their normal environment they can become pathogenic.

\section{MICROBIOTA AND HUMORAL RESPONSES}

Communication between the gut microbiota and the brain can occur via multiple routes that include the vagus nerve, gut-secreted neuropeptides, sensory nerves, cytokines, tryptophan, and SCFAs (Holzer and Farzi, 2014). See Figure 1. The brain in turn can influence gut commensals directly via the receptor-mediated signaling and signaling molecules released in the gut lumen from immune cells or epithelial cells, in particular enteroendocrine cells, or indirectly via changes in the intestinal motility and secretion (Rhee et al, 2009). Recent data suggest that the activity of microbes can also be influenced by the release into the gut lumen and uptake by microbes of miRNAs (Liu et al, 2016). While bacterial genes may be regulated by miRNAs, bacteria do not themselves produce such miRNAs.

Until relatively recently the brain was considered outside the remit of the peripheral immune system, a view now known to be incorrect. GF mice have an altered expression of genes involved in neuropeptide production (El Aidy et al,

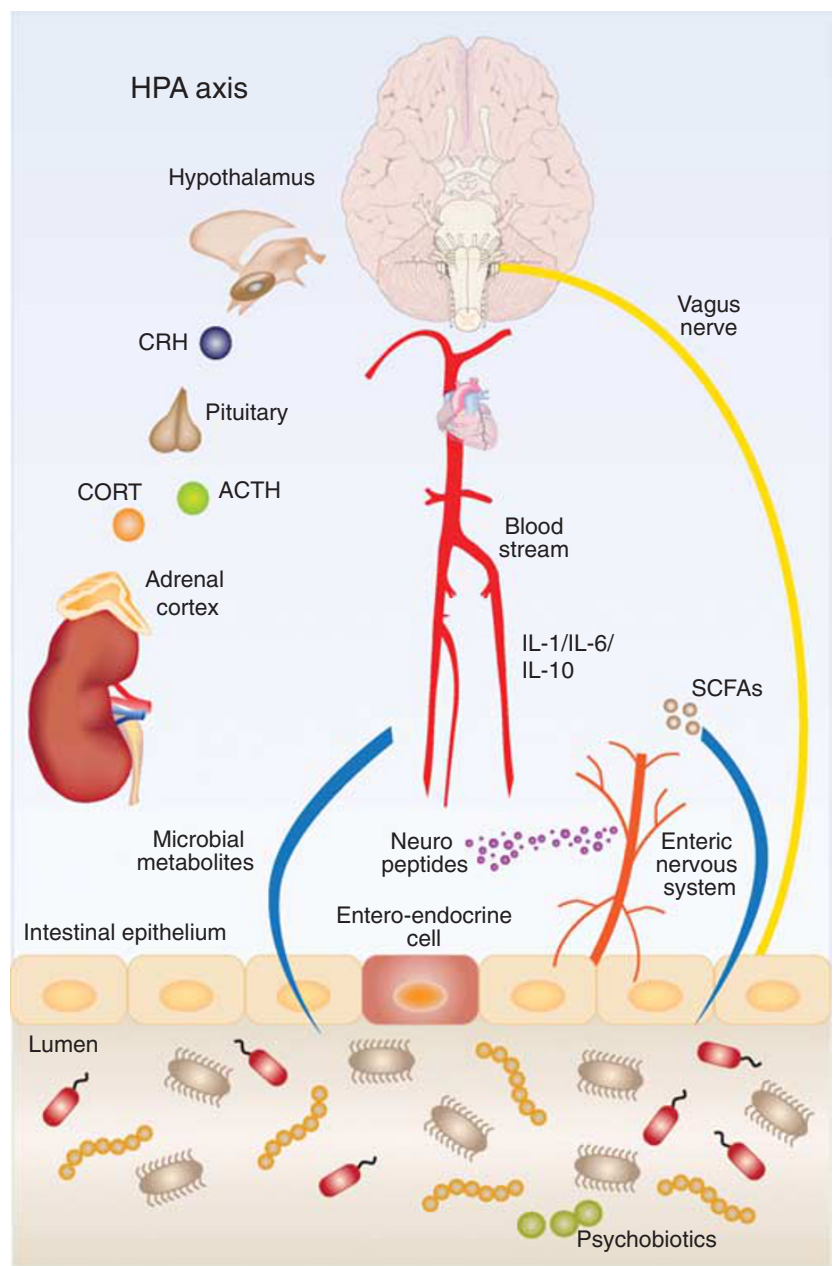

Figure 1. Routes of communication between the gut microbes and the brain include the vagus nerve, cytokines, short chain fatty acids, and tryptophan. Acting through some or all of these routes, psychobiotics induce an anti-inflammatory response and alter behavioral responses to stress.

2013) together with genes involved in brain development and behavior (Diaz Heijtz et al, 2011; Stilling et al, 2014). GF mice have significant neurochemical alterations, which are reflected in markedly altered behavior patterns including stress responses. For example they exhibit increased spontaneous motor activity compared to conventional mice (Diaz Heijtz et al, 2011) and show altered exploratory behavior, following fecal transfer from mice with anxiety-like behavior (Bercik et al, 2011). Lactobacillus rhamnosus (JB-1) reduces stress-induced corticosterone hormone levels when fed to mice. Moreover, the same strain makes the mice less anxious, an effect which is mediated by the vagus nerve and not seen following vagotomy (Bravo et al, 2011). It is also worth noting that there is an efferent vagal pathway that has been shown to have marked anti-inflammatory responses (Olofsson et al, 2012). The central mechanisms by which this bacterial strain reduces corticosterone levels has not been explored but may involve reduced release of corticotropinreleasing factor $(\mathrm{CRF})$, though alterations in negative feedback in the axis cannot be ruled out. 
The gut microbiota has been shown to produce a range of beneficial metabolites such as bacteriocins, which can help defend against bacterial infections (eg thuricin has a powerful impact against Clostridium difficile), vitamins, such as folate, cobalamin, vitamin $\mathrm{K}$, riboflavin, and thiamine, all of which are essential for human survival, and exopolysaccharides, which have prebiotic, immuno-stimulatory, antitumoral, and blood cholesterol-lowering effects (Conly and Stein, 1992; Cerning, 1995; Corr et al, 2007). More specifically a number of further microbial metabolites or 'pharmabiotics' can interact with the host's immune, neural and endocrine systems and have a profound effect on health (O'Hara and Shanahan, 2007; Shanahan, 2011). Tryptophan which is the precursor of $5-\mathrm{HT}$ is increased in the plasma of animals treated with a B. infantis (Desbonnet et al, 2008). This may be significant given the limited storage capacity for tryptophan in the mammalian brain and the requirement for a constant dietary supply.

$\gamma$-Amino butyric acid (GABA) is the main inhibitory neurotransmitter in the human brain and the target of a wide range of drugs including the benzodiazepines. GABA also plays a role in the regulation of movement, blood pressure, heart rate, and pain perception. It has been implicated in anxiety and depression (Mody et al, 1994; Cryan and Kaupmann, 2005; Schousboe and Waagepetersen, 2007). Demonstrated as involved in the control of growth hormone secretion (Volpi et al, 1997), it has protective effects against glycerol-induced acute renal failure in rats (Kim et al, 2004) and microbes secreting GABA may have antidiabetic properties (Soltani et al, 2011). Interestingly, foods enriched with GABA have been defined as 'foods for specified health use (FOSHU) in Japan' (Sanders, 1997), leading to the development of fermented products containing GABA derived from dairy, soybean, kimchi (a fermented vegetable), and juice products. However, it must be noted that GABA does not cross the blood brain barrier. It has recently been suggested that microbially produced GABA in the gut may impact the brain-gut axis (Bienenstock et al, 2010). GABA is produced by the enzyme glutamate decarboxylase and it has been hypothesized that in vivo GABA production by intestinal bacteria could have potential health benefits (Mills et al, 2009; Lyte, 2011). Lactobacilli have the necessary capacity to produce GABA and do to varying extents depending upon the individual strain and the environment. Indeed, the GABA-producing Lactobacillus brevis DPC 6108 strain has recently been shown to alter the development of diabetes in a streptozotocin rat (Marques et al, 2016).

Conjugated fatty acids, natural components of milk and tissue fat from ruminants, plant seed oils, and marine algae are positional and geometric isomers of polyunsaturated fatty acids with one or more conjugated double bonds (Chisholm and Hopkins, 1967; Burgess et al, 1991; Kohno et al, 2004; Yasui et al, 2005). Of these conjugated linoleic acid (CLA) is the most extensively studied with multiple putative health benefits including an antiatherosclerotic effect, an antiobesogenic impact, and probable anticarcinogenic properties (Bassaganya-Riera et al, 2002; Belury, 2002;
Ip et al, 2003). A number of Lactobacillus, Propionibacterium, and Bifidobacterium strains have the ability to produce these bioactive fatty acids, and in addition, Roseburia spp. has been identified among the most active producers in the gut (Devillard et al, 2007). However, there are indications that a high intake of CLA may have a pro-inflammatory action. Unlike polyunsaturated fatty acids, so far no clear mental health benefits from CLA have been identified.

Short chain fatty acids are water soluble, readily absorbed organic fatty acids of one to six carbon atoms long and are produced in the human gut as the end products of anaerobic bacterial fermentation of carbohydrates (Cummings et al, 1987). Acetate, butyrate, and propionate are the major SCFAs found in the human large intestine (Oltmer and Engelhardt, 1994). SCFAs are a major source of energy for colonic epithelial cells, are involved in the prevention of DNA and cell damage, can stimulate sodium absorption, and impact immune and inflammatory responses, while sodium butyrate has been shown to elicit an antidepressant effect in mice (Schroeder et al, 2007). It has been postulated that SCFAs can help prevent colorectal cancer and they have been reported to alter gene expression of cell cycle regulators, in vitro (Scheppach et al, 1995; Siavoshian et al, 1997; Stilling et al, 2014). As well as playing a role as epigenetic regulators by HDAC inhibition, SCFAs bind to G-protein coupled receptors (GPCRs) (Maslowski et al, 2009). Bacteria belonging to the phylum Firmicutes have been identified as the main butyrate producers in the colon, with the two most abundant groups related to Eubacterium rectale/Roseburia spp. and Faecalibacterium prausnitzii, with Faecalibacterium prausnitzii reportedly reduced in prevalence in Crohn's disease (Louis and Flint, 2009). Animal studies suggest that propionate acting centrally may play a role in the emergence of autistic-type behavior patterns and butyrate shows antidepressant effects in animal models. However, despite the fact that SCFAs can act on GPCRs the view that they have significant direct CNS effects is highly controversial. The GPCRs on which the SCFAs act are only sparsely distributed in the mammalian brain.

Serotonin (5-HT) is the most widely studied neurotransmitter in relation to psychiatric illness. Produced from tryptophan it plays a key role in multiple processes and only a small percentage of 5-HT is found in the brain with over $90 \%$ found in the GI tract (Keszthelyi et al, 2009). In the gut it is mainly stored in the enterochromaffin cells of the intestinal mucosa and the remainder in the serotonergic neurons of the enteric nervous system (Keszthelyi et al, 2009). Most antidepressants currently marketed impact 5-HT (Cryan and O'Leary, 2010). It has been shown that the gut microbiota plays a role in the production of serotonin (Wikoff et al, 2009) and the plasma serotonin levels of conventional mice are almost three-fold higher than GF mice (Wikoff et al, 2009). Furthermore, B. infantis has been reported to increase levels of the serotonin precursor, tryptophan, in the plasma of rats and shows antidepressant activity in rodent tests such as the forced swim test (FST) (Desbonnet et al, 2008). Recently, Hsiao and colleagues 
have shown that certain strains of spore-forming bacteria produced metabolites which affect the production of serotonin that in turn impacts host physiological functions (Yano et al, 2015).

Endocannabinoids are lipid molecules whose receptor sites are found widely distributed in the brain (Piomelli, 2003). Such receptors also bind $\delta^{9}$-tetrahydro-cannabinol, the active ingredient in cannabis, a plant long known for its psychotrophic activities including a tendency for the emergence of psychotic symptoms (Piomelli, 2003). Endocannabinoids, along with their receptors, play a role in the bioactive lipid signaling system in the central nervous system and in various peripheral organs and have been implicated in the pathogenesis of cardiovascular diseases (Batkai and Pacher, 2009). There is increasing evidence to indicate that the endocannabinoid system and the gut microbiota can affect the development of obesity and related disorders. They also have the potential to modulate pain perception. Lactobacillus acidophilus has been reported to modulate expression of cannabinoid receptors and reduce abdominal pain in rodents (Rousseaux et al, 2007).

One investigated mechanism through which immune activation may alter behavior is via actions on serotonergic systems (Lowry et al, 2007). The nonpathogenic Mycobacterium vaccae leads to activation of the peripheral immune system. The Th1 and Treg, but not Th2, mediated immune activation stimulates a subset of 5-HT neurons in the dorsal raphe nucleus of mice and increases serotonin turnover in the ventromedial prefrontal cortex (Lowry et al, 2007). This finding illustrates the fact that the type of peripheral immune response determines the effects on central 5-HT neurons. Furthermore, the findings suggest that the immuneresponsive subpopulation of serotonergic neurons in the dorsal raphe play a role in the regulation of mood. It has been suggested that afferent fibers within the vagus nerve are involved in transferring signals of peripheral immune activation to the CNS. Immune activation under normal conditions stimulates a subset of 5-HT neurons, different from those activated under pathological states. Immune activation can induce depression and anxiety and is also associated with disorders of the brain-gut axis such as irritable bowels syndrome (Clarke et al, 2009). Immune activation induced by interferon therapy frequently results in the emergence of depressive symptoms. Treatment with selective serotonin reuptake inhibitors prevents the onset of depressive symptoms in such situations (Capuron and Miller, 2004). Moreover, recent data have shown that the anti-TNF antibody infliximab can reduce features of depression.

Local and systemic depletion of the 5-HT precursor, tryptophan is associated with elevation of the immunomodulatory enzyme indoleamine-pyrrole 2,3-dioxygenase (IDO), which occurs during immune activation (Moffett and Namboodiri, 2003) and transiently during primary gut colonization. The ability of the gut microbiota to control host tryptophan metabolism along the kynurenine pathway is gaining attention (O'Mahony et al, 2015). This reduces the fraction available for serotonin synthesis and increases the production of neuroactive and immunoresponsive metabolites (O'Mahony et al, 2015).

Local and systemic increases in pro-inflammatory cytokines such as IL-1 and IL- 6 bring about activation of the hypothalamic-pituitary-adrenal (HPA) axis and production of CRF. corticotropin-releasing factor, which is also elevated by psychological stress, causes disturbance to other neuropeptides, leading to changes in mood and behavior (Dinan and Cryan, 2012). It is interesting from an evolutionary perspective that both physical stressors such as microbial pathogens and psychological stress activate the HPA, albeit through somewhat different mechanisms. CRF stimulates the anterior pituitary gland to release the stress hormone; ACTH, which in turn stimulates release of cortisol from the adrenal gland. Cortisol, through a feedback loop, regulates the levels of CRF and ACTH. Importantly, immune cells, through the COX-2 pathway and production of PEG-2 during (pro-) inflammation, stimulate the adrenal gland to produce cortisol, which supports the $\beta$ adrenergic pathway in its anti-inflammatory effect (Straub et al, 2006). This indicates that under normal conditions the neuroendocrine and immune systems coordinate to maintain homeostasis.

Bacterial by-products that come in contact with the gut epithelium stimulate the production of several neuropeptides including peptide YY, neuropeptide Y, cholecystokinin, glucagon-like peptide-1,2, and substance $\mathrm{P}$ and oxytocin (Furness et al, 2013). Following secretion, neuropeptides diffuse throughout the lamina propria, which is occupied by a variety of immune cells, until they reach the blood stream, stimulate sensory neurons or act on the vagus nerve (Cummings and Overduin, 2007; Okano-Matsumoto et al, 2011). The exact mechanisms by which neuropeptides communicate with the CNS are poorly understood. Bohorquez et al described a neuroepithelial circuit that acts as both sensory channels for food and gut microbes and transmits messages from the lumen to the ENS and CNS and also in reverse (Bohorquez et al, 2015). Neuropeptides overall represent an important route of dialogue between but microbes and the host.

\section{MICROBES, GUT BARRIER, AND INFLAMMATION}

The main function of the intestinal barrier is to regulate the absorption of nutrients, electrolytes, and water from the lumen into the circulation and to prevent the entry of pathogens and toxins (Kelly et al, 2015). Furthermore, regulation of the exchange of molecules between the environment and the host through the intestinal barrier influences the equilibrium between tolerance and immunity to self and non-self-antigens (Fasano, 2011). From a structural perspective these functions are preserved by a number of features including a mucus layer and a monolayer of epithelial cells interconnected by tight junctions. The mucus layer containing $\operatorname{sg} \mathrm{A}$ and antimicrobial peptides 
cover the epithelial cell lining which functions to facilitate GI transport, and as a protective layer against bacterial invasion. The colonic mucus layer is composed of two layers, an outer and inner layer composed of gel forming highly glycosylated proteins termed mucins. These are produced and maintained by goblet cells, which renew the inner mucus layer on a regular basis (Johansson et al, 2011). The dynamic processes are subject to extensive and continuous interplay with the gut microbiota, disruption of which may have implications for the maintenance of key barrier functions (Bischoff et al, 2014).

Tight junctions are complex protein structures that consist of transmembrane proteins such as claudin, occludin, and tricullulin (Cording et al, 2013). These transmembrane proteins connect with the opposing plasma membrane, thereby forming a mechanical link between epithelial cells and establishing a barrier to paracellular. It has been shown that the structure of the intestinal barrier is formed by the end of the first trimester of pregnancy (Kelly et al, 2015). Epithelial cells with microvilli, goblet, and enteroendocrine cells appear by week 8 of gestation and tight junctions are detected from week 10. Continued functional development of the intestinal barrier continues in the after birth and is influenced significantly by diet (Verhasselt, 2010). Disruptions in this process are seen in the underdevelopment of the intestinal barrier of the premature infant, which predisposes to immune disorders. There is an overlapping developmental trajectory of the gut microbiota and intestinal barrier. As described above, the gut microbiota, in the initial days of life, is unstable and lacks diversity. By age three, however, the microbiota composition resembles that of an adult-like profile (Voreades et al, 2014). The intestinal barrier acts as a protective defense that can be modified by the gut microbiota or its metabolites. The mechanisms underlying the regulation of the epithelial barrier are complex and only partially understood. The role of the gut microbiota in disrupting the intestinal barrier in stress-related conditions, such as depression, has not been adequately investigated. In animal models of depression gut barrier function is disrupted (O'Mahony et al, 2011) and there is a narrowing in the diversity of gut microbes and a pro-inflammatory cytokine profile. It is tempting to speculate that these factors are causally related but this has yet to be convincingly demonstrated.

\section{MICROBIOTA AS A REGULATOR OF NEUROIMMUNE FUNCTION}

Microglia are the resident macrophage-like cells of the brain and thus the key immune cells that sense environmental changes in the brain and regulate neuroinflammatory processes (Yamasaki et al, 2014). Microglia once activated are critically involved in neuronal events at various stages in development and adulthood, including synaptic remodeling to improve neuronal network signaling (Schafer and Stevens, 2015). An increasing body of evidence suggests a link between microglia and the microbiota-gut-brain axis which has implications for many stress-related and neurodegenerative disorders (Cryan and Dinan, 2015) There is a close link between HPA axis activation and the regulation of the peripheral and central immune responses, leading to monocyte priming and trafficking, subsequent alterations in microglia phenotype and, ultimately resulting in neuroinflammation. Indeed such neuroinflammatory responses are implicated in a number of psychiatric disorders, including anxiety and depression (Hodes et al, 2015; Miller and Raison, 2015). Microglia activation and subsequent release of cytokines plays a causal role in the manifestation of behavioral phenotypes in a variety of rodent stress models (Kreisel et al, 2014).

Intriguingly, a critical role for gastrointestinal microbiota in all aspects of microglia maturation, morphology, and immunological function has been uncovered (Erny et al, 2015). In contrast, the absence of a complex host microbiota (as evidenced by GF models or using antibiotic suppression of microbiota) led to increased microglial populations; defects in microglia maturation, activation state, and differentiation; alterations to microglia morphology (with longer processes and increased branching, terminal points and clubbing at synaptic boutons); and a compromised immune response to bacterial or viral infection (Erny et al, 2015). The observed alterations in microglial phenotype were reversed with recolonization of gut microbiota, following 6 weeks co-habitation of GF mice with control mice. The findings from this study have redefined the construct of targeting brain processes through the gut. It should also be noted that minocycline, a semi-synthetic, second-generation tetracycline analogue can effectively cross the blood-brain barrier and has been reported to exert neuroprotective effects in cerebral ischemia, traumatic brain injury, amyotrophic lateral sclerosis, Parkinson's disease, kainic acid treatment, Huntington' disease, multiple sclerosis, and Alzheimer's in various preclinical animal models; reportedly through suppression of microglia activation (Tikka et al, 2001). However, minocycline has a dual action as antibiotic and thus may be influencing centrally mediated events indirectly through microbiota depletion, where it acts on both grampositive and gram-negative bacteria.

\section{MICROBIOTA AND STROKE}

Given the accumulating role for microbiome in regulating key processes involved in neuroimmune function such as microglia activation and blood brain barrier integrity (Braniste et al, 2014) in addition to those brain processes critically regulated by neuroinflammation such as adult hippocampal neurogenesis and myelination (Hoban et al, 2016), it is thus not too surprising that a link with the microbiome and stroke/brain injury has been put forward. In an intriguing recent study antibiotic-induced alterations in the microbiota resulted in a markedly reduced ischemic brain injury in mice, an effect transmissible by fecal 
transplants (Winek et al, 2016). Immune mechanisms are driving such effects as alterations in microbiome composition indices, changes in immune homeostasis in the small intestine, leading to an increase in Treg cells and a reduction in interleukin (IL)-17-positive $\gamma \delta \mathrm{T}$ cells through altered DC activity. Moreover, changing microbiota composition unmasks a heretofore unknown suppression of the trafficking of effector $\mathrm{T}$ cells from the gut to the leptomeninges after stroke. Additionally, IL-10 and IL-17 are required for the neuroprotection afforded by intestinal dysbiosis (Benakis et al, 2016).

Using a different approach recent studies have showed that targeting the microbiome, using a specific bacterial strain that produces SCFAs, Clostridium butyricum attenuated the enhanced cognitive impairment, cell damage, and apoptosis induced in a stroke model in both normal (Sun et al, 2016) and in a diabetic mouse model (Sun et al, 2016).

\section{MICROBIOTA AND SCHIZOPHRENIA}

Dinan et al argued strongly that the gut microbiota might play an important role in schizophrenia (Dinan et al, 2014). However, to date little systematic analysis has taken place in this field. In a small-scale study of the oro-pharyngeal microbiota alterations were observed (Castro-Nallar et al, 2015). A shotgun metagenomic analysis of the oropharyngeal microbiome in 16 individuals with schizophrenia and 16 controls was undertaken. High-level differences were evident at both the phylum and genus levels, with Proteobacteria, Firmicutes, Bacteroidetes, and Actinobacteria dominating both schizophrenia patients and controls, and Ascomycota being more abundant in schizophrenia. The authors conclude that overall the microbiome of schizophrenia patients was characterized by an increased number of metabolic pathways related to metabolite transport systems including siderophores, glutamate, and vitamin B12.

\section{MICROBIOTA, IMMUNITY, AND DEPRESSION}

Depression is a pro-inflammatory state associated with the presence of biomarkers of inflammation such as elevated interleukin IL-6, TNF $\alpha$ and the acute phase protein, C reactive protein (Dinan, 2009). Similar elevated biomarkers of inflammation have been seen in anxiety states and are known to occur as a result of stress. Furthermore, the site at which these pro-inflammatory molecules is produced in depression is not known and it has yet to be established that gut-microbe-immune interactions are central to the elevation. With impairment in gut barrier function and resultant increased gut permeability translocation of gut bacteria across the intestinal wall occurs and into the mesenteric lymphoid tissue. It is speculated that increased exposure of the mucosal immune cells to bacteria can activate an immune response and lead to release of inflammatory cytokines with stimulation of the vagus nerve and spinal afferent neurons. Furthermore, increased permeability of the gut can also increase the translocation of metabolic products or neuroactive substances produced by the bacteria and cause altered activity centrally. For a detailed review of this process, see Yarandi et al (2016). There is evidence from rodent studies to indicate that stress alters the gut barrier function allowing lipopolysaccharide and other molecules to gain access to the bloodstream stimulating TLR4 and other TLRs resulting in the production of inflammatory cytokines (Kelly et al, 2015). Formyl peptide receptors (FPRs) may also play a role (Dahlgren et al, 2016). These receptors are involved in host defense against microbial intruders and in regulating inflammatory reactions. FPR1 and FPR2 are expressed in neutrophils and bind many structurally diverse activating and inhibiting ligands. If altered barrier function occurs in depression with microbial or microbial metabolite translocation and stimulation of key pattern recognition receptors it would help explain the pro-inflammatory phenotype observed.

While an infectious etiology of mood disorders is not currently a major focus of research, in the past, infectious diseases were thought to be the cause of many psychiatric disorders. Brucellosis, which is associated with dairy farming, provides a good example of an infective agent that can result in depression. It has been shown that approximately $30 \%$ of patients with brucellosis are depressed and the presence of depression is independent of whether or not there is CNS involvement (Shehata et al, 2010). How is such a syndrome induced and is it possible that commensal bacteria may have a reverse action and alleviate depressive symptoms? As documented above, the evidence points to the fact that immune activation in the periphery can lead to central neurotransmitter changes. Pathogenic bacteria in doses that do not elicit sickness behavior can also bring about central changes. Lyte et al (1998) have shown that oral administration of the pathogen Campylobacter jejuni, in subclinical doses, which were too low to elicit an immune response, resulted in anxiety-like behavior in mice. They also found that areas of brainstem activation, most notably the nucleus tractus solitarius and lateral parabrachial nucleus, participate in neural information processing that lead to autonomic, neuroendocrine, and behavioral responses.

The gut microbiota has been found altered in the maternal separation model of depression, where a narrowing in diversity has been reported (O'Mahony et al, 2009). In a more recent study the gut microbiota was profiled in patients with major depression (Jiang et al, 2015). Major depressives had increased levels of Enterobacteriaceae and Alistipes but reduced levels of Faecalibacterium. A negative correlation was observed between Faecalibacterium and the severity of depressive symptoms. In another investigation several correlations between microbial composition and depression were reported in a study of 37 depressed patients and 18 healthy controls (Naseribafrouei et al, 2014). The order Bacteroidales was over-represented. The altered nutritional status of depressives and the impact of psychotropic medication cannot be entirely ruled out in inducing the changes seen in either of these studies. It is also clear that 
given the nature of depression far greater sample sizes need to be recruited.

A small but interesting study has recently further linked mood states with microbiota composition. The research took advantage of the closed human life support system used by astronauts in training during a 105-day period. Gut microbial community structures were analyzed every 2 weeks as was a profile of mood states questionnaire. Bacterial genera Roseburia, Phascolarctobacterium, Lachnospira, and Prevotella had potential positive correlation with positive mood, while genera Faecalibacterium, Bifidobacterium, Bacteroides, Parabacteroides, and Anaerostipes were correlated with negative mood. Among which, Faecalibacterium spp. had the highest abundance, and showed a significant negative correlation with mood (Li et al, 2016).

\section{MICROBIOTA-IMMUNE TARGET OF ANTIDEPRESSANTS}

It has been hypothesized that the major classes of antidepressants work, in addition to their effects on central monoamines by the generation of the potent immunoregulatory effects and as a consequence suppressing inflammation and the CNS changes associated with depression (Raison and Miller, 2013). In this regard, it is interesting that the immunoregulatory effects of probiotic microorganisms are also thought to occur through the generation of $\mathrm{T}$ regs and the synthesis and secretion of IL-10 (Lavasani et al, 2010). Feeding of a commensal bacteria to GF mice results in local DC uptake and alteration of phenotype to one which promotes $\mathrm{T}$ reg production and IL-10 synthesis. Ingestion of Lactobacillus $G G$ has been suggested as a therapeutic in management of several conditions and has been shown to upregulate IL-10 in the plasma. While IL-10 has potent anti-inflammatory properties, it is also thought to act directly as an anti-nociceptive agent, indicating that it has broad neuroimmune effects, but impact on behavior has not to date been reported. The intestinal microbial balance may alter the regulation of inflammatory responses and in so doing may be involved in the modulation of mood and behavior (Cryan and Dinan, 2012; El Aidy et al, 2016).

As mentioned above, the hyper-response of the HPA in GF mice is reversed by mono-association with a single organism, $B$. infantis, which is a predominant bacterium in the infant gut and a commonly used probiotic organism. Furthermore, in GF animals the levels of norepinephrine (NE) and 5-HT in the cortex and hippocampus are significantly reduced (Clarke et al, 2013). Thus, preclinical data clearly show that commensal bacteria have the capability of altering not only the HPA axis but key neurotransmitters thought to be of relevance in the etiology of depression.

We have assessed the potential benefits of the probiotic B. infantis in the rat maternal separation model of depression, a paradigm that has proven to be of value in the study of antidepressant effects (Desbonnet et al, 2010).
Maternally separated adult rat offspring were chronically treated with $B$. infantis or a selective serotonin reuptake inhibitor (citalopram) and subjected to the FST to assess motivational state. Cytokine concentrations in stimulated whole blood samples, monoamine levels in the brain, and central and peripheral HPA measures were also analyzed. Maternal separation reduced swim behavior and increased immobility in the FST, decreased noradrenaline content in the brain, and enhanced pro-inflammatory peripheral IL-6 release and amygdala CRF mRNA levels. Probiotic treatment resulted in reversal of behavioral deficits, normalization of immune response, and restoration of basal noradrenaline concentrations in the brainstem. $B$. infantis has been shown in patients with IBS to alter the ratio of pro- to antiinflammatory cytokines in the plasma (O'Mahony et al, 2005). Overall, preclinical data strongly support the view that an aberrant microbiota can alter behavior, immunity, and endocrinology and point to an influential role for Bifidobacterium in neural function (McKernan et al, 2010). L. rhamnosus whose effects have been described previously produces marked anxiolytic effects in animals acting through central GABA (Bravo et al, 2011). Vagotomy prevented the emergence of an anxiolytic effect from the probiotic and prevented changes in GABA receptor expression.

Prebiotics that increase the levels of 'good' bacteria in the intestine have been demonstrated to affect stress responses in animal models, but more importantly to reduce the awakening cortisol response in healthy volunteers (Schmidt et al, 2015). While the prebiotics FOS and GOS have been found useful in treating the metabolic syndrome, to date they have not been tested in patients with depression or other stress-related disorders.

In a double-blind, placebo-controlled, randomized parallel group study volunteers received either the probiotic combination L. helveticus R0052 and B. longum or placebo for 30 days and were assessed by the Hopkins Symptom Checklist (HSCL-90), the Hospital Anxiety and Depression Scale (HADS), the Perceived Stress Scale, the Coping Checklist (CCL) (Messaoudi et al, 2011). Daily administration of probiotic combination significantly reduced psychological distress in volunteers, as measured by the HSCL-90 scale, the HADS, and by the CCL. Furthermore, urinary-free cortisol levels were significantly reduced by the probiotics, providing a potential mechanism for the improvement in psychological symptoms observed and we have also observed that a strain of $B$. longum significantly reduced the awakening salivary cortisol response in healthy subjects relative to that seen with placebo.

Another study found that the consumption of a probioticcontaining yoghurt improved mood (Benton et al, 2007). One hundred and thirty-two physically healthy subjects with a mean age 61.8 years volunteered in response to local media coverage. One hundred and twenty-four completed the trial. For a 3-week period, either a probiotic containing milk drink, or a placebo were consumed daily. Mood and cognition were measured at baseline, and after 10 and 20 days of consumption. When the third with the lowest baseline mood 
were considered, they selectively responded by reporting themselves as happy rather than depressed after taking the probiotic.

The focus to date has largely been on the modulation of host-immune interactions using probiotic organisms that might benefit mental health. Such bacteria have been defined as psychobiotic (Dinan et al, 2013). However, the possibility that depleting the microbiota of certain potentially melancholic-inducing bacterial strains has also been explored, though to a lesser extent. Minocycline, the tetracycline antibiotic, in small-scale studies has been found effective in treating the symptoms of both depression (Miyaoka et al, 2012) and schizophrenia (Khodaie-Ardakani et al, 2014). As mentioned above, these findings are usually explained on the basis that minocycline inhibits the microglia polarization to a pro-inflammatory state and reduces pro-inflammatory cytokine levels (Hinwood et al, 2012). Such an analysis, while focused on what is now a definite and frequently reproduced observation, ignores the fact that minocycline is first and foremost an antibiotic that impacts both gram-positive and gram-negative bacteria. It is plausible that the therapeutic effects of minocycline occur primarily by an action on the gut microbiota. Careful studies are required to tease apart the microglial stabilizing effects of the minocycline from its classic antibiotic action.

\section{MICROBIOTA TRANSPLANTATION}

In recent times we have seen a broadening of the indication for fecal microbiota transplantation (FMT) beyond the narrow remit of treating Clostridium difficile infection (Xu et al, 2015). Recently, a double blind trial of 18 patients with metabolic syndrome was reported. Half received a transplant from a lean donor and half an auto-fecal transplant (Vrieze et al, 2012). Transplant from the lean donors resulted in improved insulin sensitivity and alterations in SCFAs. The control group failed to show such changes. Targeting the microbiota has resulted in improvement in a case study of a patient with Parkinson's disease and it has been shown that a full truncal vagotomy decreases the risk of the disorder as individuals enter old age (Gray et al, 2015). There are also case reports of improvement in patients with multiple sclerosis and autism following FMT (Xu et al, 2015). Proper controlled studies are clearly required. Given the pre-clinical data in animal models of stress-related disorders, it is intriguing to speculate that FMT might be beneficial in conditions such as treatment refractory depression. To date no such studies have been reported and will undoubtedly be subject to serious regulatory scrutiny.

\section{FUTURE RESEARCH DIRECTIONS: FOCUS ON NOVEL TARGETS}

We are still at the very early stages of understanding the complex communication systems between gut bacteria, immunity, and behavior, but it is now established that certain bacteria within the human gut play a fundamental role in immune development and have the ability to produce molecules with neuroactive properties which can impact brain physiology and behavior. However, while metagenomics has advanced our understanding of the diversity of bacteria within the gut, the reality is that many of these bacteria remain unculturable and only a limited number of bacterial strains, which may be psychoactive, have been tested in vivo. Moreover, complex microbial ecosystems such as in the human gut are difficult to mimic and interactions between bacteria cannot be studied by simple culture conditions in vitro. We therefore require in vivo studies to determine the role of metabolite-producing bacteria and what affect such bacteria, and their components parts and metabolites have on the immune system and subsequently on the brain and behavior. Such studies will facilitate our understanding of the consequences of neuroactive compound production by the microbiota and how probiotic bacteria can influence the CNS, and could furthermore identify probiotic bacteria which have psychobiotic potential for the treatment of psychiatric disorders such as depression. However, while we have seen a recent massive expansion in preclinical studies there is a marked shortage of translational investigations. Nonetheless, immune modulation of behavior via the gut microbiota offers exciting and intriguing potential for innovative treatments in psychiatry.

\section{FUNDING AND DISCLOSURE}

The authors are supported in part by Science Foundation Ireland in the form of a center grant (Alimentary Pharmabiotic Centre Grant Number SFI/12/RC/2273); by the Health Research Board of Ireland (Grant Numbers HRA_POR/2011/23 and HRA_POR/2012/32) and received funding from the European Community's Seventh Framework Programme Grant MyNewGut under Grant Agreement No. FP7/2007-2013. The authors collaborate with Cremo, Suntory Wellness, 4D Pharma, Danone-Nutricia and Mead Johnson.

\section{REFERENCES}

Ader R, Cohen N, Felten D (1995). Psychoneuroimmunology: interactions between the nervous system and the immune system. Lancet 345: 99-103.

Adlerberth I, Wold AE (2009). Establishment of the gut microbiota in Western infants. Acta Paediatr. 98: 229-238.

Arboleya S, Binetti A, Salazar N, Fernandez N, Solis G, Hernandez-Barranco A et al (2012). Establishment and development of intestinal microbiota in preterm neonates. Fems Microbiology Ecology 79: 763-772.

Arumugam M, Raes J, Pelletier E, Le Paslier D, Yamada T, Mende DR et al (2011). Enterotypes of the human gut microbiome. Nature 473: 174-180.

Atarashi K, Tanoue T, Shima T, Imaoka A, Kuwahara T, Momose Y et al (2011). Induction of colonic regulatory $T$ cells by indigenous Clostridium species. Science 331: 337-341.

Backhed F (2011). Programming of host metabolism by the gut microbiota. Ann Nutr Metab 58: 44-52.

Barrett E, Deshpandey AK, Ryan CA, Dempsey EM, Murphy B, O'Sullivan L et al (2015). The neonatal gut harbours distinct bifidobacterial strains. Arch Dis Child Fetal Neonatal Ed 100: F405-F410.

Bassaganya-Riera J, Hontecillas R, Beitz DC (2002). Colonic anti-inflammatory mechanisms of conjugated linoleic acid. Clin Nutr 21: 451-459. 
Batkai S, Pacher P (2009). Endocannabinoids and cardiac contractile function: pathophysiological implications. Pharmacol Res 60: 99-106.

Belury MA (2002). Inhibition of carcinogenesis by conjugated linoleic acid: potential mechanisms of action. J Nutr 132: 2995-2998.

Benakis C, Brea D, Caballero S, Faraco G, Moore J, Murphy M et al (2016). Commensal microbiota affects ischemic stroke outcome by regulating intestinal gammadelta T cells. Nat Med 22: 516-523.

Benson AK, Kelly SA, Legge R, Ma FR, Low SJ, Kim J et al (2010). Individuality in gut microbiota composition is a complex polygenic trait shaped by multiple environmental and host genetic factors. Proc Natl Acad Sci USA 107 18933-18938.

Benton D, Williams C, Brown A (2007). Impact of consuming a milk drink containing a probiotic on mood and cognition. Eur J Clin Nutr 61: 355-361.

Bercik P, Denou E, Collins J, Jackson W, Lu J, Jury J et al (2011). The intestinal microbiota affect central levels of brain-derived neurotropic factor and behavior in mice. Gastroenterology 141: 599-609, 609.e591-e593.

Bested AC, Logan AC, Selhub EM (2013). Intestinal microbiota, probiotics and mental health: from Metchnikoff to modern advances: Part II-contemporary contextual research. Gut Pathog 5: 3.

Bienenstock J, Forsythe P, Karimi K, Kunze W (2010). Neuroimmune aspects of food intake. Int Dairy J 20: 253-258.

Bischoff SC, Barbara G, Buurman W, Ockhuizen T, Schulzke JD, Serino M et al (2014). Intestinal permeability - a new target for disease prevention and therapy. BMC Gastroenterol 14: 189

Boehm G, Moro G (2008). Structural and functional aspects of prebiotics used in infant nutrition. J Nutr 138: 1818S-1828S.

Bohorquez DV, Shahid RA, Erdmann A, Kreger AM, Wang Y, Calakos N et al (2015). Neuroepithelial circuit formed by innervation of sensory enteroendocrine cells. J Clin Invest 125: 782-786.

Borre YE, O'Keeffe GW, Clarke G, Stanton C, Dinan TG, Cryan JF (2014). Microbiota and neurodevelopmental windows: implications for brain disorders. Trends $\mathrm{Mol}$ Med 20: 509-518.

Braniste V, Al-Asmakh M, Kowal C, Anuar F, Abbaspour A, Toth M et al (2014). The gut microbiota influences blood-brain barrier permeability in mice. Sci Trans/ Med 6: 263 ra158

Bravo JA, Forsythe P, Chew MV, Escaravage E, Savignac HM, Dinan TG et al (2011). Ingestion of Lactobacillus strain regulates emotional behavior and central GABA receptor expression in a mouse via the vagus nerve. Proc Natl Acad Sci USA 108: 16050-16055.

Burgess JR, Delarosa RI, Jacobs RS, Butler A (1991). A new eicosapentaenoic acid fromed from arachidonic-acid in the coralline red algae Bossiella orbigniana. Lipids 26: 162-165.

Burke C, Steinberg P, Rusch D, Kjelleberg S, Thomas T (2011). Bacterial community assembly based on functional genes rather than species. Proc Natl Acad Sci USa 108: 14288-14293.

Castro-Nallar E, Bendall ML, Perez-Losada M, Sabuncyan S, Severance EG, Dickerson FB et al (2015). Composition, taxonomy and functional diversity of the oropharynx microbiome in individuals with schizophrenia and controls. Peer $\mathrm{J}$ 3: e1140

Capuron L, Miller AH (2004). Cytokines and psychopathology: lessons from interferon-alpha. Biol Psychiatry 56: 819-824.

Cerning J (1995). Production of exopolysaccharides by lactic acid bacteria and dairy propionibacteria. Lait 75: 463-472.

Chang JY, Shin SM, Chun J, Lee J-H, Seo J-K (2011). Pyrosequencing-based molecular monitoring of the intestinal bacterial colonization in preterm infants. J Pediatr Gastroenterol Nutr 53: 512-519.

Chisholm MJ, Hopkins CY (1967). Conjugated fatty acids in some cucurbitaceae seed oils. Can J Biochem 45: 1081-108.

Chung H, Pamp SJ, Hill JA, Surana NK, Edelman SM, Troy EB et al (2012). Gut immune maturation depends on colonization with a host-specific microbiota. Cell 149: 1578-1593.

Claesson MJ, Cusack S, O'Sullivan O, Greene-Diniz R, de Weerd H, Flannery E et al (2011). Composition, variability, and temporal stability of the intestinal microbiota of the elderly. Proc Natl Acad Sci USA 108: 4586-4591.

Clarke G, Grenham S, Scully P, Fitzgerald P, Moloney RD, Shanahan F et al (2013). The microbiome-gut-brain axis during early life regulates the hippocampal serotonergic system in a sex-dependent manner. Mol Psychiatry 18: 666-673.

Clarke G, Quigley EM, Cryan JF, Dinan TG (2009). Irritable bowel syndrome: towards biomarker identification. Trends Mol Med 15: 478-489.

Claud EC, Walker WA (2001). Hypothesis: inappropriate colonization of the premature intestine can cause neonatal necrotizing enterocolitis. Faseb $\mathrm{J}$ 15: 1398-1403.

Clemente JC, Ursell LK, Parfrey LW, Knight R (2012). The impact of the gut microbiota on human health: an integrative view. Cell 148: 1258-1270.
Conly JM, Stein K (1992). The production of menaquinones (vitamin K2) by intestinal bacteria and their role in maintaining coagulation homeostasis. Prog Food Nutr Sci 16: 307-343.

Cording J, Berg J, Kading N, Bellmann C, Tscheik C, Westphal JK et al (2013). In tight junctions, claudins regulate the interactions between occludin, tricellulin and marvelD3, which, inversely, modulate claudin oligomerization. J Cell Sci 126 554-564.

Corr SC, Li Y, Riedel CU, O'Toole PW, Hill C, Gahan CGM (2007). Bacteriocin production as a mechanism for the antfinfective activity of Lactobacillus salivarius UCC118. Proc Nat Acad Sci USA 104: 7617-7621.

Costello EK, Stagaman K, Dethlefsen L, Bohannan BJ, Relman DA (2012). The application of ecological theory toward an understanding of the human microbiome. Science 336: 1255-1262.

Cryan JF, Dinan TG (2012). Mind-altering microorganisms: the impact of the gut microbiota on brain and behaviour. Nat Rev Neurosci 13: 701-712.

Cryan JF, Dinan TG (2015). Gut microbiota: microbiota and neuroimmune signallingMetchnikoff to microglia. Nat Rev Gastroenterol Hepatol 12: 494-496.

Cryan JF, Kaupmann K (2005). Don't worry 'B' happy!: a role for GABA(B) receptors in anxiety and depression. Trends Pharmacol Sci 26: 36-43.

Cryan JF, O'Leary OF (2010). A glutamate pathway to faster-acting antidepressants? Science's STKE 329: 913.

Cummings DE, Overduin J (2007). Gastrointestinal regulation of food intake. J Clin Invest 117: 13-23.

Cummings JH, Pomare EW, Branch WJ, Naylor CP, Macfarlane GT (1987). Short chain fatty acids in human large intestine, portal, hepatic and venous blood. Gut 28: $1221-1227$.

Dahlgren C, Gabl M, Holdfeldt A, Winther M, Forsman H (2016). Basic characteristics of the neutrophil receptors that recognize formylated peptides, a dangerassociated molecular pattern generated by bacteria and mitochondria. Biochem Pharmacol (in press).

Dennison B (1976). Definition of preterm delivery. Br Med J 2: 1449-1449.

Desbonnet L, Garrett L, Clarke G, Bienenstock J, Dinan TG (2008). The probiotic Bifidobacteria infantis: an assessment of potential antidepressant properties in the rat. J Psychiatr Res 43: 164-174.

Desbonnet L, Garrett L, Clarke G, Kiely B, Cryan JF, Dinan TG (2010). Effects of the probiotic Bifidobacterium infantis in the maternal separation model of depression. Neuroscience 170: 1179-1188.

Deshpande G, Rao S, Patole S (2007). Probiotics for prevention of necrotising enterocolitis in preterm neonates with very low birthweight: a systematic review of randomised controlled trials. Lancet 369: 1614-1620.

Devillard E, McIntosh FM, Duncan SH, Wallace RJ (2007). Metabolism of linoleic acid by human gut bacteria: different routes for biosynthesis of conjugated linoleic acid. J Bacteriol 189: 2566-2570.

Diaz Heijtz R, Wang S, Anuar F, Qian Y, Bjorkholm B, Samuelsson A et al (2011). Normal gut microbiota modulates brain development and behavior. Proc Nat Acad Sci USA 108: 3047-3052.

Dinan TG (2009). Inflammatory markers in depression. Curr Opin Psychiatry 22 32-36.

Dinan TG, Cryan JF (2012). Regulation of the stress response by the gut microbiota: implications for psychoneuroendocrinology. Psychoneuroendocrinology 37: 1369-1378.

Dinan TG, Stanton C, Cryan JF (2013). Psychobiotics: a novel class of psychotropic. Biol Psychiatry 74: 720-726.

Dinan TG, Borre YE, Cryan JF (2014). Genomics of schizophrenia: time to consider the gut microbiome? Mol Psychiatry 19: 1252-1257.

Eckburg PB, Bik EM, Bernstein CN, Purdom E, Dethlefsen L, Sargent M et al (2005). Diversity of the human intestinal microbial flora. Science 308: 1635-1638.

El Aidy S, Derrien M, Aardema R, Hooiveld G, Richards SE, Dane A et al (2014). Transient inflammatory-like state and microbial dysbiosis are pivotal in establishment of mucosal homeostasis during colonisation of germ-free mice. Benef Microbes 5: 67-77.

El Aidy S, Dinan TG, Cryan JF (2015). Gut microbiota: the conductor in the orchestra of immune-neuroendocrine communication. Clin Ther 37: 954-967.

El Aidy S, Kleerebezem M (2013). Molecular signatures for the dynamic process of establishing intestinal host-microbial homeostasis: potential for disease diagnostics? Curr Opin Gastroenterol 29: 621-627.

El Aidy S, Merrifield CA, Derrien M, van Baarlen P, Hooiveld G, Levenez F et al (2013). The gut microbiota elicits a profound metabolic reorientation in the mouse jejunal mucosa during conventionalisation. Gut 62: 1306-1314.

El Aidy S, Stilling R, Dinan TG, Cryan JF (2016). Microbiome to brain: unravelling the multidirectional axes of communication. Adv Exp Med Biol 874: 301-336.

El Aidy S, van Baarlen $P$, Derrien $M$, Lindenbergh-Kortleve DJ, Hooiveld G, Levenez F et al (2012). Temporal and spatial interplay of microbiota and intestinal mucosa drive establishment of immune homeostasis in conventionalized mice. Mucosal Immunol 5: 567-579. 
Embleton ND, Yates R (2008). Probiotics and other preventative strategies for necrotising enterocolitis. Semin Fetal Neonatal Med 13: 35-43.

Erny D, de Angelis ALH, Jaitin D, Wieghofer P, Staszewski O, David E et al (2015). Host microbiota constantly control maturation and function of microglia in the CNS. Nat Neurosci 18: 965-977.

Fanaro S, Boehm G, Garssen J, Knol J, Mosca F, Stahl B et al (2005). Galactooligosaccharides and long-chain fructo-oligosaccharides as prebiotics in infant formulas: a review. Acta Paediatr 94: 22-26.

Fasano A (2011). Zonulin and its regulation of intestinal barrier function: the biological door to inflammation, autoimmunity, and cancer. Physiol Rev 91: 151-175.

Fitzgibbons SC, Ching YM, Yu D, Carpenter J, Kenny M, Weldon C et al (2009). Mortality of necrotizing enterocolitis expressed by birth weight categories. J Pediatr Surg 44: 1072-1076.

Flint HJ, O'Toole PW, Walker AW (2010). Special issue: the human intestinal microbiota. Microbiology-Sgm 156: 3203-3204.

Frieri M, Stampfl H (2016). Systemic lupus erythematosus and atherosclerosis: review of the literature. Autoimmun Rev 15: 16-21.

Furness JB, Rivera LR, Cho HJ, Bravo DM, Callaghan B (2013). The gut as a sensory organ. Nat Rev Gastroenterol Hepatol 10: 729-740.

Gaboriau-Routhiau V, Lecuyer E, Cerf-Bensussan N (2011). Role of microbiota in postnatal maturation of intestinal T-cell responses. Curr Opin Gastroenterol 27: 502-508.

Gaboriau-Routhiau V, Rakotobe S, Lecuyer E, Mulder I, Lan A, Bridonneau C et al (2009). The key role of segmented filamentous bacteria in the coordinated maturation of gut helper T cell responses. Immunity 31: 677-689.

Galindo-Villegas J, Garcia-Moreno D, de Oliveira S, Meseguer J, Mulero V (2012). Regulation of immunity and disease resistance by commensal microbes and chromatin modifications during zebrafish development. Proc Natl Acad Sci USA 109: E2605-E2614.

Gareau MG, Sherman PM, Walker WA (2010). Probiotics and the gut microbiota in intestinal health and disease. Nat Rev Gastroenterol Hepatol 7: 503-514.

Gibson GR, Roberfroid MB (1995). Dietary modulation of the human colonic microbiota-introducing the concept of prebiotics. J Nutr 125: 1401-1412.

Glaser R, Kiecolt-Glaser JK (2005). Stress-induced immune dysfunction: implications for health. Nat Rev Immunol 5: 243-251.

Gomez de Aguero M, Ganal-Vonarburg SC, Fuhrer T, Rupp S, Uchimura Y, Li H et al (2016). The maternal microbiota drives early postnatal innate immune development. Science 351: 1296-1302.

Gray MT, Munoz DG, Schlossmacher MG, Gray DA, Woulfe JM (2015). Protective effect of vagotomy suggests source organ for Parkinson disease. Ann Neurol 78: 834-835.

Haarman M, Knol J (2005). Quantitative real-time PCR assays to identify and quantify fecal Bifidobacterium species in infants receiving a prebiotic infant formula. Appl Environ Microbiol 71: 2318-2324.

Harmsen HJM, Wildeboer-Veloo ACM, Raangs GC, Wagendorp AA, Klijn N, Bindels JG et al (2000). Analysis of intestinal flora development in breast-fed and formula-fed infants by using molecular identification and detection methods. J Pediatr Gastroenterol Nutr 30: 61-67.

Heumann D, Barras C, Severin A, Glauser MP, Tomasz A (1994). Gram-positive cell walls stimulate synthesis of tumor necrosis factor alpha and interleukin- 6 by human monocytes. Infect Immun 62: 2715-2721.

Hinwood M, Morandini J, Day TA, Walker FR (2012). Evidence that microglia mediate the neurobiological effects of chronic psychological stress on the medial prefrontal cortex. Cereb Cortex 22: 1442-1454.

Hoban AE, Stilling RM, Ryan FJ, Shanahan F, Dinan TG, Claesson MJ et al (2016). Regulation of prefrontal cortex myelination by the microbiota. Transl Psychiatry 6: e774.

Hodes GE, Kana V, Menard C, Merad M, Russo SJ (2015). Neuroimmune mechanisms of depression. Nat Neurosci 18: 1386-1393.

Holzer P, Farzi A (2014). Neuropeptides and the microbiota-gut-brain axis. Adv Exp Med Biol 817: 195-219.

Hoy CM, Wood CM, Hawkey PM, Puntis JWL (2000). Duodenal microflora in verylow-birth-weight neonates and relation to necrotizing enterocolitis. J Clin Microbiol 38: 4539-4547.

Ip MM, Masso-Welch PA, Ip C (2003). Prevention of mammary cancer with conjugated linoleic acid: role of the stroma and the epithelium. J Mammary Gland Biol Neoplasia 8: 103-118.

Jacquot A, Neveu D, Aujoulat F, Mercier G, Marchandin H, Jumas-Bilak E et al (2011). Dynamics and clinical evolution of bacterial gut microflora in extremely premature patients. J Pediatr 158: 390-396.

Jiang H, Ling Z, Zhang Y, Mao H, Ma Z, Yin Y et al (2015). Altered fecal microbiota composition in patients with major depressive disorder. Brain Behav Immun 48: 186-194.

Jimenez E, Marin ML, Martin R, Odriozola JM, Olivares M, Xaus $J$ et al (2008). Is meconium from healthy newborns actually sterile? Res Microbiol 159: 187-193.
Johansson ME, Larsson JM, Hansson GC (2011). The two mucus layers of colon are organized by the MUC2 mucin, whereas the outer layer is a legislator of hostmicrobial interactions. Proc Natl Acad Sci USA 108(Suppl 1): 4659-4665.

Johansson ME, Sjovall H, Hansson GC (2013). The gastrointestinal mucus system in health and disease. Nat Rev Gastroenterol Hepatol 10: 352-361.

Kassinen A, Krogius-Kurikka L, Makivuokko H, Rinttila T, Paulin L, Corander J et al (2007). The fecal microbiota of irritable bowel syndrome patients differs significantly from that of healthy subjects. Gastroenterology 133: 24-33.

Keles S, Artac H, Kara R, Gokturk B, Ozen A, Reisli I (2010). Transient hypogammaglobulinemia and unclassified hypogammaglobulinemia: 'similarities and differences'. Pediatr Allergy Immunol 21: 843-851.

Kelly JR, Kennedy PJ, Cryan JF, Dinan TG, Clarke G, Hyland NP (2015). Breaking down the barriers: the gut microbiome, intestinal permeability and stress-related psychiatric disorders. Front Cell Neurosci 9: 392.

Keszthelyi D, Troost FJ, Masclee AAM (2009). Understanding the role of tryptophan and serotonin metabolism in gastrointestinal function. Neurogastroenterology and Motility 21: 1239-1249.

Khodaie-Ardakani MR, Mirshafiee O, Farokhnia M, Tajdini M, Hosseini SM, Modabbernia A et al (2014). Minocycline add-on to risperidone for treatment of negative symptoms in patients with stable schizophrenia: randomized doubleblind placebo-controlled study. Psychiatry Res 215: 540-546.

Kim HY, Yokozawa T, Nakagawa TK, Sasaki S (2004). Protective effect of gammaaminobutyric acid against glycerol-induced acute renal failure in rats. Food and Chem Toxicol 42: 2009-2014.

Koenig JE, Spor A, Scalfone N, Fricker AD, Stombaugh J, Knight R et al (2011). Succession of microbial consortia in the developing infant gut microbiome. Proc Natl Acad Sci USA 108: 4578-4585.

Kohno H, Yasui Y, Suzuki R, Hosokawa M, Miyashita K, Tanaka T (2004). Dietary seed oil rich in conjugated linolenic acid from bitter melon inhibits azoxymethane-induced rat colon carcinogenesis through elevation of colonic PPAR gamma expression and alteration of lipid composition. Int J Cancer 110: 896-901.

Kosloske AM (1984). Pathogenesis and prevention of necrotizing enterocolitis-a hypothesis based on personal observation and a review of the literature. Pediatrics 74: 1086-1092.

Kostic AD, Howitt MR, Garrett WS (2013). Exploring host-microbiota interactions in animal models and humans. Genes Dev 27: 701-718.

Kotiranta-Ainamo A, Rautonen J, Rautonen N (2004). Imbalanced cytokine secretion in newborns. Biol Neonate 85: 55-60.

Kreisel T, Frank MG, Licht T, Reshef R, Ben-Menachem-Zidon O, Baratta MV et al (2014). Dynamic microglial alterations underlie stress-induced depressive-like behavior and suppressed neurogenesis. Mol Psychiatry 19: 699-709.

Lavasani S, Dzhambazov B, Nouri M, Fak F, Buske S, Molin G et al (2010). A novel probiotic mixture exerts a therapeutic effect on experimental autoimmune encephalomyelitis mediated by IL-10 producing regulatory T cells. PLoS One 5: e9009.

Lee YK, Menezes JS, Umesaki Y, Mazmanian SK (2011). Proinflammatory T-cell responses to gut microbiota promote experimental autoimmune encephalomyelitis. Proc Natl Acad Sci U S A 108(Suppl 1): 4615-4622.

Ley RE, Turnbaugh PJ, Klein S, Gordon JI (2006). Microbial ecology-human gut microbes associated with obesity. Nature 444: 1022-1023.

Li L, Su Q, Xie B, Duan L, Zhao W, Hu D et al (2016). Gut microbes in correlation with mood: case study in a closed experimental human life support system. Neurogastroenterol Motil (in press).

Liu S, da Cunha AP, Rezende RM, Cialic R, Wei Z, Bry L et al (2016). The host shapes the gut microbiota via fecal microRNA. Cell Host Microbe 19: 32-43.

Louis P, Flint HJ (2009). Diversity, metabolism and microbial ecology of butyrate-producing bacteria from the human large intestine. Fems Microbiol Lett 294: 1-8.

Lowry CA, Hollis JH, de Vries A, Pan B, Brunet LR, Hunt JR et al (2007). Identification of an immune-responsive mesolimbocortical serotonergic system: potential role in regulation of emotional behavior. Neuroscience 146: 756-772.

Lyte M (2011). Probiotics function mechanistically as delivery vehicles for neuroactive compounds: Microbial endocrinology in the design and use of probiotics. Bioessays 33: 574-581.

Lyte M, Varcoe JJ, Bailey MT (1998). Anxiogenic effect of subclinical bacterial infection in mice in the absence of overt immune activation. Physiol Behav 65: 63-68.

Mackie RI, Sghir A, Gaskins HR (1999). Developmental microbial ecology of the neonatal gastrointestinal tract. Am J Clin Nutr 69: 1035S-1045S.

Macpherson AJ, Geuking MB, McCoy KD (2005). Immune responses that adapt the intestinal mucosa to commensal intestinal bacteria. Immunology 115: 153-162.

Mariat D, Firmesse O, Levenez F, Guimaraes VD, Sokol H, Dore J et al (2009). The Firmicutes/Bacteroidetes ratio of the human microbiota changes with age. Bmc Microbiology 9: 123-129.

Marques TM, Patterson E, Wall R, O'Sullivan O, Fitzgerald GF, Cotter PD et al (2016). Influence of GABA and GABA-producing Lactobacillus brevis DPC 6108 on the 
development of diabetes in a streptozotocin rat model. Benef Microbes 7: 409-420.

Marques TM, Wall R, Ross RP, Fitzgerald GF, Ryan CA, Stanton C (2010). Programming infant gut microbiota: influence of dietary and environmental factors. Curr Opin Biotechnol 21: 149-156.

Maslowski KM, Vieira AT, Ng A, Kranich J, Sierro F, Yu D et al (2009). Regulation of inflammatory responses by gut microbiota and chemoattractant receptor GPR43. Nature 461: 1282-U1119.

Mazmanian SK, Liu CH, Tzianabos AO, Kasper DL (2005). An immunomodulatory molecule of symbiotic bacteria directs maturation of the host immune system. Cell 122: $107-118$.

McKernan DP, Fitzgerald P, Dinan TG, Cryan JF (2010). The probiotic Bifidobacterium infantis 35624 displays visceral antinociceptive effects in the rat. Neurogastroenterol Motil 22: 1029-1035, e1268.

Messaoudi M, Lalonde R, Violle N, Javelot H, Desor D, Nejdi A et al (2011). Assessment of psychotropic-like properties of a probiotic formulation (Lactobacillus helveticus R0052 and Bifidobacterium longum R0175) in rats and human subjects. Br J Nutr 105: 755-764.

Mikkelsen HB, Garbarsch C, Tranum-Jensen J, Thuneberg L (2004). Macrophages in the small intestinal muscularis externa of embryos, newborn and adult germfree mice. J Mol Histol 35: 377-387.

Miller AH, Raison CL (2015). The role of inflammation in depression: from evolutionary imperative to modern treatment target. Nat Rev Immunol 16: 22-34.

Mills S, Stanton C, Ross RP (2009). Microbial production of bioactives: from fermented functional foods to probiotic mechanisms. Aust J Dairy Technol 64: 41-49.

Miyaoka T, Wake R, Furuya M, Liaury K, leda M, Kawakami K et al (2012). Minocycline as adjunctive therapy for patients with unipolar psychotic depression: an open-label study. Prog Neuropsychopharmacol Biol Psychiatry 37: 222-226.

Mody I, Dekoninck Y, Otis TS, Soltesz I (1994). Bridging the cleft at GABA synapses in the brain. Trends Neurosci 17: 517-525.

Moffett JR, Namboodiri MA (2003). Tryptophan and the immune response. Immunol Cell Biol 81: 247-265.

Mshvildadze M, Neu J (2009). Probiotics and prevention of necrotizing enterocolitis. Early Hum Dev 85: S71-S74.

Mueller S, Saunier K, Hanisch C, Norin E, Alm L, Midtvedt T et al (2006). Differences in fecal microbiota in different European study populations in relation to age, gender, and country: a cross-sectional study. Appl Environ Microbiol 72: 1027-1033.

Naseribafrouei A, Hestad K, Avershina E, Sekelja M, Linløkken A, Wilson R et al (2014). Correlation between the human faecal microbiota and depression. Neurogastroenterol Motil 26: 1155-1162.

Neu J, Walker WA (2011). Medical progress: necrotizing enterocolitis. N Engl J Med 364: 255-264.

Newburg DS, Walker WA (2007). Protection of the neonate by the innate immune system of developing gut and of human milk. Pediatr Res 61: 2-8.

O'Hara AM, Shanahan F (2007). Mechanisms of action of probiotics in intestinal diseases. Thescientificworldjournal 7: 31-46.

O'Mahony L, McCarthy J, Kelly P, Hurley G, Luo F, Chen K et al (2005). Lactobacillus and bifidobacterium in irritable bowel syndrome: symptom responses and relationship to cytokine profiles. Gastroenterology 128: 541-551.

O'Mahony SM, Clarke G, Borre YE, Dinan TG, Cryan JF (2015). Serotonin, tryptophan metabolism and the brain-gut-microbiome axis. Behav Brain Res 277: 32-48.

O'Mahony SM, Hyland NP, Dinan TG, Cryan JF (2011). Maternal separation as a model of brain-gut axis dysfunction. Psychopharmacology (Berl) 214: 71-88.

O'Mahony SM, Marchesi JR, Scully P, Codling C, Ceolho AM, Quigley EM et al (2009). Early life stress alters behavior, immunity, and microbiota in rats: implications for irritable bowel syndrome and psychiatric illnesses. Biol Psychiatry 65: 263-267.

O'Toole PW, Claesson MJ (2010). Gut microbiota: changes throughout the lifespan from infancy to elderly. Int Dairy J 20: 281-291.

Okano-Matsumoto S, McRoberts JA, Tache Y, Adelson DW (2011). Electrophysiological evidence for distinct vagal pathways mediating CCK-evoked motor effects in the proximal versus distal stomach. J Physiol 589: 371-393.

Olofsson PS, Rosas-Ballina M, Levine YA, Tracey KJ (2012). Rethinking inflammation: neural circuits in the regulation of immunity. Immunol Rev 248: 188-204.

Olszak T, D An, Zeissig S, Vera MP, Richter J, Franke A et al (2012). Microbial exposure during early life has persistent effects on natural killer $\mathrm{T}$ cell function. Science 336: 489-493.

Oltmer S, Engelhardt WV (1994). Absorption of short-chain fatty acids from the insitu-perfused caecum and colon of the guinea pig. Scand J Gastroenterol 29: 1009-1016.

Palmer C, Bik EM, DiGiulio DB, Relman DA, Brown PO (2007). Development of the human infant intestinal microbiota. Plos Biol 5: 1556-1573.
Penders J, Thijs C, Vink C, Stelma FF, Snijders B, Kummeling I et al (2006). Factors influencing the composition of the intestinal microbiota in early infancy. Pediatrics 118: $511-521$.

Peterson DA, Frank DN, Pace NR, Gordon Jl (2008). Metagenomic approaches for defining the pathogenesis of inflammatory bowel diseases. Cell Host Microbe 3 : $417-427$.

Piomelli D (2003). The molecular logic of endocannabinoid signalling. Nat Rev Neurosci 4: 873-884.

Qin J, Li R, Raes J, Arumugam M, Burgdorf KS, Manichanh C et al (2010). A human gut microbial gene catalogue established by metagenomic sequencing. Nature 464: U59-U70.

Raison CL, Miller AH (2013). Role of inflammation in depression: implications for phenomenology, pathophysiology and treatment. Mod Trends Pharmacopsychiatri 28: 33-48.

Rawls JF, Mahowald MA, Ley RE, Gordon JI (2006). Reciprocal gut microbiota transplants from zebrafish and mice to germ-free recipients reveal host habitat selection. Cell 127: 423-433.

Reis WL, Yi CX, Gao Y, Tschop MH, Stern JE (2015). Brain innate immunity regulates hypothalamic arcuate neuronal activity and feeding behavior. Endocrinology 156: 1303-1315.

Rhee SH, Pothoulakis C, Mayer EA (2009). Principles and clinical implications of the brain-gut-enteric microbiota axis. Nat Rev Gastroenterol Hepatol 6: 306-314.

Round JL, Mazmanian SK (2009). The gut microbiota shapes intestinal immune responses during health and disease. Nat Rev Immunol 9: 313-323.

Rousseaux C, Thuru X, Gelot A, Barnich N, Neut C, Dubuquoy L et al (2007). Lactobacillus acidophilus modulates intestinal pain and induces opioid and cannabinoid receptors. Nat Med 13: 35-37.

Sanders ME (1997). Overview of functional foods: emphasis on probiotic bacteria. In: Symposium on Functional Foods-Designer Foods for the Future. Elsevier Sci Ltd: Cork, Ireland.

Saulnier DMA, Spinler JK, Gibson GR, Versalovic J (2009). Mechanisms of probiosis and prebiosis: considerations for enhanced functional foods. Curr Opin Biotechnol 20: 135-141.

Schafer DP, Stevens B (2015). Microglia function in central nervous system development and plasticity. Cold Spring Harb Perspect Biol 7: a020545.

Scheppach W, Bartram HP, Richter F (1995). Role of short chain fatty acids in the prevention of colorectal cancer. Eur J Cancer 31A: 1077-1080.

Schmidt K, Cowen PJ, Harmer CJ, Tzortzis G, Errington S, Burnet PW (2015). Prebiotic intake reduces the waking cortisol response and alters emotional bias in healthy volunteers. Psychopharmacology (Berl) 232: 1793-1801.

Schousboe A, Waagepetersen HS (2007). GABA: homeostatic and pharmacological aspects. In: Tepper JM, Abercrombie ED, Bolam JP (eds). Gaba and the Basal Ganglia: From Molecules to Systems, vol. 160. Elsevier Science Bv: Amsterdam. pp 9-19.

Schroeder FA, Lin CL, Crusio WE, Akbarian S (2007). Antidepressant-like effects of the histone deacetylase inhibitor, sodium butyrate, in the mouse. Biol Psychiatry 62: 55-64.

Shanahan F (2011). The colonic microflora and probiotic therapy in health and disease. Curr Opin Gastroenterol 27: 61-65.

Shanahan $F$ (2012). the gut microbiota in 2011: translating the microbiota to medicine. Nat Rev Gastroenterol Hepatol 9: 72-74.

Shehata GA, Abdel-Baky L, Rashed H, Elamin H (2010). Neuropsychiatric evaluation of patients with brucellosis. J Neurovirol 16: 48-55.

Shulzhenko N, Morgun A, Hsiao W, Battle M, Yao M, Gavrilova O et al (2011). Crosstalk between B lymphocytes, microbiota and the intestinal epithelium governs immunity versus metabolism in the gut. Nat Med 17: 1585-1593.

Siavoshian S, Blottiere HM, LeFoll E, Kaeffer B, Cherbut C, Galmiche JP (1997). Comparison of the effect of different short chain fatty acids on the growth and differentiation of human colonic carcinoma cell lines in vitro. Cell Biol Int 21: 281-287.

Soltani N, Qiu HM, Aleksic M, Glinka Y, Zhao F, Liu R et al (2011). GABA exerts protective and regenerative effects on islet beta cells and reverses diabetes. Proc Natl Acad Sci USA 108: 11692-11697.

Sondheimer JM, Clark DA (1985). Gastric pH in healthy preterm infants-effect of age and feeding type. Gastroenterology 88: 1593-1593.

Sondheimer JM, Clark DA, Gervaise EP (1985). Continuous gastric pH measurement in young and older healthy preterm infants receiving formula and clear liquid feedings. J Pediatr Gastroenterol Nutr 4: 352-355.

Sonnenburg ED, Smits SA, Tikhonov M, Higginbottom SK, Wingreen NS, Sonnenburg JL (2016). Diet-induced extinctions in the gut microbiota compound over generations. Nature 529: 212-215.

Stark PL, Lee A (1982). The microbial ecology of the large bowel of breast-fed and formula-fed infants during the first year of life. J Med Microbio/ 15: 189-203.

Stilling RM, Dinan TG, Cryan JF (2014). Microbial genes, brain \& behaviourepigenetic regulation of the gut-brain axis. Genes Brain Behav 13: 69-86. 
Straub RH, Wiest R, Strauch UG, Harle P, Scholmerich J (2006). The role of the sympathetic nervous system in intestinal inflammation. Gut 55: 1640-1649.

Sun J, Ling Z, Wang F, Chen W, Li H, Jin J et al (2016). Clostridium butyricum pretreatment attenuates cerebral ischemia/reperfusion injury in mice via antioxidation and anti-apoptosis. Neurosci Lett 613: 30-35.

Sun J, Wang F, Ling Z, Yu X, Chen W, Li H et al (2016). Clostridium butyricum attenuates cerebral ischemia/reperfusion injury in diabetic mice via modulation of gut microbiota. Brain Res 1642: 180-188.

Surana NK, Kasper DL (2014). Deciphering the tete-a-tete between the microbiota and the immune system. J Clin Invest 124: 4197-4203.

Tikka T, Fiebich BL, Goldsteins G, Keinanen R, Koistinaho J (2001). Minocycline, a tetracycline derivative, is neuroprotective against excitotoxicity by inhibiting activation and proliferation of microglia. J Neurosci 21: 2580-2588.

Turnbaugh PJ, Ley RE, Mahowald MA, Magrini V, Mardis ER, Gordon JI (2006). An obesity-associated gut microbiome with increased capacity for energy harvest. Nature 444: 1027-1031.

Turnbaugh PJ, Quince C, Faith JJ, McHardy AC, Yatsunenko T, Niazi F et al (2010). Organismal, genetic, and transcriptional variation in the deeply sequenced gut microbiomes of identical twins. Proc Natl Acad Sci USA 107: 7503-7508.

Ulevitch RJ, Tobias PS (1995). Receptor-dependent mechanisms of cell stimulation by bacterial endotoxin. Annu Rev Immunol 13: 437-457.

Vaughan EE, Schut F, Heilig H, Zoetendal EG, de Vos WM, Akkermans ADL (2000). A molecular view of the intestinal ecosystem. Current Issues Intest Microbiol 1: $1-12$.

Velilla PA, Rugeles MT, Chougnet CA (2006). Defective antigen-presenting cell function in human neonates. Clin Immunol 121: 251-259.

Verhasselt V (2010). Oral tolerance in neonates: from basics to potential prevention of allergic disease. Mucosal Immunol 3: 326-333.

Volpi R, Chiodera P, Caffarra P, Scaglioni A, Saccani A, Coiro V (1997). Different control mechanisms of growth hormone $(\mathrm{GH})$ secretion between gamma-aminoand gamma-hydroxy-butyric acid: neuroendocrine evidence in Parkinson's disease. Psychoneuroendocrinology 22: 531-538.

Voreades N, Kozil A, Weir TL (2014). Diet and the development of the human intestinal microbiome. Front Microbio 5: 494-503.

Vrieze A, Van Nood E, Holleman F, Salojarvi J, Kootte RS, Bartelsman JF et al (2012). Transfer of intestinal microbiota from lean donors increases insulin sensitivity in individuals with metabolic syndrome. Gastroenterology 143: 913-916, e917.

Wassenaar TM, Panigrahi P (2014). Is a foetus developing in a sterile environment? Lett Appl Microbio/ 59: 572-579.

Wei B, Wingender G, Fujiwara D, Chen DY, McPherson M, Brewer S et al (2010). Commensal microbiota and CD8+ $T$ cells shape the formation of invariant NKT cells. J Immunol 184: 1218-1226.

Westerbeek EAM, van den Berg A, Lafeber HN, Knol J, Fetter WPF, van Elburg RM (2006). The intestinal bacterial colonisation in preterm infants: a review of the literature. Clin Nutr 25: 361-368.

Wieland Brown LC, Penaranda C, Kashyap PC, Williams BB, Clardy J, Kronenberg M et al (2013). Production of alpha-galactosylceramide by a prominent member of the human gut microbiota. PLoS Biol 11: e1001610.

Wikoff WR, Anfora AT, Liu J, Schultz PG, Lesley SA, Peters EC et al (2009). Metabolomics analysis reveals large effects of gut microflora on mammalian blood metabolites. Proc Natl Acad Sci USA 106: 3698-3703.

Winek K, Meisel A, Dirnagl U (2016). Gut microbiota impact on stroke outcome: fad or fact? J Cereb Blood Flow Metab 36: 891-898.

Wu GD, Chen J, Hoffmann C, Bittinger K, Chen YY, Keilbaugh SA et al (2011). Linking long-term dietary patterns with gut microbial enterotypes. Science 333: 105-108.

Xu MQ, Cao HL, Wang WQ, Wang S, Cao XC, Yan F et al (2015). Fecal microbiota transplantation broadening its application beyond intestinal disorders. World $J$ Gastroenterol 21: 102-111.

Yamasaki R, Lu H, Butovsky O, Ohno N, Rietsch AM, Cialic Ret al (2014). Differential roles of microglia and monocytes in the inflamed central nervous system. J Exp Med 211: 1533-1549.

Yano JM, Yu K, Donaldson GP, Shastri GG, Ann P, Ma L et al (2015). Indigenous bacteria from the gut microbiota regulate host serotonin biosynthesis. Cell 161: 264-276.

Yarandi SS, Peterson DA, Treisman GJ, Moran TH, Pasricha PJ (2016). Modulatory effects of gut microbiota on the central nervous system: how gut could play a role in neuropsychiatric health and diseases. I Neurogastroenterol Motil 22: 201-212.

Yasui Y, Hosokawa M, Sahara T, Suzuki R, Ongiya S, Kohno H et al (2005). Bitter gourd seed fatty acid rich in 9c,11t,13t-conjugated linolenic acid induces apoptosis and up-regulates the GADD45, p53 and PPAR gamma in human colon cancer Caco-2 cells. Prostaglandins Leukot Essent Fatty Acids 73: 113-119. 